\author{
В. М. Вдовиченко ${ }^{\varpi}$, Д. С. Ганжа** \\ * Дніпровський начіональний університет імені Олеся Гончара, \\ просп. Гагаріна, 72, м. Дніпро, Украӥна, 49010 \\ ** Природний заповідник «Дніпровсько-Орільський», \\ вул. Полетаєва, 2, м. Дніпро, Украӥна, 49054

\section{РОСЛИННИЙ ПОКРИВ НА ЗГАРИЩАХ АРЕНИ РІКИ САМАРИ В МЕЖАХ ДЕРЖАВНОГО ПІДПРИЕМСТВА «НОВОМОСКОВСЬКИЙ ВІЙСЬКОВИЙ ЛІСГОСП»}

Досліджено рослинний покрив на території Державного підприємства «Новомосковський військовий лісгосп» на ділянках, що зазнали негативного впливу низових лісових пожеж за останні 10 років та був запущений процес пірогенних сукцесій. При дослідженні проводився детальний опис відповідно до типології Бельгарда О. Л. Було помічено, що екологічну нішу, яка звільнилась під впливом низової пожежі, активно освоюють трав'янисті рослини, переважно злакові. Дані дослідження показують певні закономірності пірогенних сукцесій i дають можливість прогнозувати такі зміни на інших ділянках та проводити відповідні заходи щодо лісовідновлення, лісорозведення, догляду за лісовими культурами та інших лісогосподарських заходів.

Ключові слова: пірогенні сукцесії, лісова пожежа, рослинний покрив, екологічна ніша.

\author{
V. N. Vdovychenko $\square *$, D. S. Ganzha** \\ *Oles Honchar Dnipro National University, Dnipro, Ukraine \\ **Dniprovsko-Orilsky Nature Reserve, Dnipro, Ukraine
}

\title{
SURFACE COVERING ON THE FLOORS OF THE SAMARA RIVER AREA WITHIN THE «NOVOMOSKOVSK MILITARY FORESTRY» OF THE STATE ENTERPRISE
}

It was conducted an ecomorph analysis of plant communities in the arena of the Samara river. The vegetation cover of the territory of the State Enterprise «Novomoskovsky Military Forestry» in the areas of lower forest fires over the past 10 years was investigated and the process of pyrogenic successions was launched. Vegetation is an essential component of biogeocoenosis, which provides vital activity for other biotic components. Therefore, changes in vegetation under the influence of various environmental factors affect the state biogeocoenosis in general. Environmental analysis of plant communities allows qualitative assessment of plant communities and their comparison by composition of cenomorph, klimamorph, heliomorf, termomorf, trophomorf and hygromorf. It was estimated the environmental specific of phytocenosis communities, which is the basis for the development of their environmentally sound storage. It was determined that significant part of the phytocenosis communities is taken by perennials. The species composition of

Tel.: +38066-725-39-21. E-mail: v_v-m@ukr.net

DOI: $10.15421 / 441908$ 
herbaceous plant communities is dominated by plants from the families Asteraceae and Poaseae. The presence of a large number of weeds demonstrates the instability of the ecosystem. In the presence of forest and weed-forest species of herbs. In dry conditions, steppe species are present. Rare plants such as Stipa borysthenica have been discovered. It is included in the red book of Ukraine. A detailed description of the flora and classification of plant communities according to the typology of A. Belgard was made. As a result of studies, it was established that grassy plants, mainly cereals, are actively mastering the ecological niche, which was freed up under the influence of a ground fire. Studies show certain patterns of pyrogenic successions and make it possible to predict such changes in other similar areas and carry out appropriate measures for reforestation, afforestation, care of forest crops and other forestry activities.

Key words: pyrogenic successions, wildfire, vegetation, ecological niche.

\section{Вступ}

Лісові пожежі є небезпечним стихійним лихом. Вони завдають величезних збитків та нищать лісові екосистеми. Навіть при сучасному рівні розвитку технологій пожежі залишаються світовою проблемою. Невтішна статистика повідомляє, що винуватцями близько 95 \% лісових пожеж є антропогенний фактор [1]. Пожежа як стихійне явище запускає цілий ряд змін в екосистемах. Деякі види рослин можуть проростати 3 насінин лише після термічної обробки. Види, які вижили, після пожежі виходять на перший план і стають домінантами. Такі зміни прийнято називати пірогенними сукцесіями.

Нами було досліджено рослинний покрив на згарищах соснових насаджень у межах ДП «Новомосковський військовий лісгосп». У результаті пожеж з 2002 по 2018 рік виникло 588 пожеж, як наслідок було пошкоджено 4015,39 га, в тому числі верховою пожежею 785,90 га переважно соснового лісу [2].

Новоутворені біогеоценози на місцях пожеж мають свої особливості в умовах арени ріки Самари. Алювіальні піски арени Самари, що утворились у післяльодовикову епоху, мають свої особливості: низьку трофність, високі перепади добових та сезонних температур, не мають поверхневого стоку, добре аеровані. Самарський ліс $\epsilon$ південною межею природного ареалу сосни звичайної, що оселилась на піщаних грунтах з верхових борів по мірі відступу на північ вюрмського льодовика [5].

Природні соснові ліси були майже повністю знищені на півдні України у XIX та початку XX ст. Поступово замінювались штучними насадженнями, які швидко натуралізувались в умовах екологічної відповідності [3]. На жаль, вони дуже потерпають від пожеж, причиною яких $є$ антропогенний фактор [1].

\section{Матеріали та методи досліджень}

Для дослідження рослинного покриву на згарищах ДП «Новомосковський військовий лісгосп» нами було закладено 11 пробних площ по $100 \mathrm{~m}^{2}$ у кварталах 137, 158, 179, 180, 191, 203, 204, 208. На площах проводився ретельний геоботанічний опис, складались анотовані списки рослин для подальшого аналізу за типами екоморф Бельгарда $[3,6]$.

\section{Результати та їх обговорення}

У межах дослідженої території, після впливу пожежі, було виконано біоекологічну паспортизацію наявних рослин (табл. 1). 
Таблиия 1

Біоекологічна характеристика рослин на місцях, пройдених пожежею

\begin{tabular}{|c|c|c|c|c|c|c|c|c|}
\hline Види рослин & 离言 & 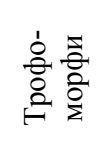 & 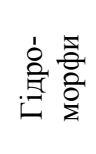 & 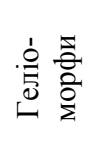 & $\begin{array}{l}\text { 点 } \\
\text { 㥕 } \\
\text { 恶 }\end{array}$ & 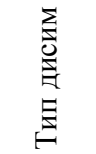 & 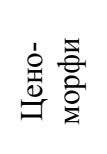 & Родини \\
\hline 1 & 2 & 3 & 4 & 5 & 6 & 7 & 8 & 9 \\
\hline $\begin{array}{l}\text { 1. Achillea micrantha } \\
\text { Willd. }\end{array}$ & $\mathrm{HKr}$ & $\operatorname{Og} \operatorname{Tr}$ & MsKs & $\mathrm{ScHe}$ & Ent & Bal & St-Pr & Asteraceae \\
\hline 2. Allium savrancum Bess. & G & $\mathrm{Og} \operatorname{Tr}$ & MsKs & $\mathrm{He}$ & Ent & Bal & St-Ps & Alliaceae \\
\hline $\begin{array}{l}\text { 3. Alyssum tortuosum } \\
\text { Waldst. et Kit. }\end{array}$ & $\mathrm{HKr}$ & $\operatorname{MsTr}$ & Ks & $\mathrm{He}$ & Ent & Bar & Ptr-Ps & Brassicaceae \\
\hline $\begin{array}{l}\text { 4. Anthemis ruthenica } \\
\text { Bieb. }\end{array}$ & $\mathrm{T}$ & $\operatorname{Og} \operatorname{Tr}$ & MsKs & $\mathrm{ScHe}$ & Ent & Bal & $\mathrm{Ps}-\mathrm{Ru}$ & Asteraceae \\
\hline $\begin{array}{l}\text { 5. Artemisia marschalliana } \\
\text { SprenG }\end{array}$ & $\mathrm{HKr}$ & $\begin{array}{l}\mathrm{OgMs} \\
\mathrm{Tr}\end{array}$ & MsKs & $\mathrm{He}$ & Anph & Bal & $\begin{array}{l}\text { Pr-St- } \\
\text { Ps }\end{array}$ & Asteraceae \\
\hline $\begin{array}{l}\text { 6. Astragalus varius S. G } \\
\text { Gmel. }\end{array}$ & $\mathrm{HKr}$ & $\operatorname{Og} \operatorname{Tr}$ & Ks & $\mathrm{He}$ & Ent & Bal & Ps-St & Fabaceae \\
\hline 7. Atriplex tatarica L. & $\mathrm{T}$ & $\begin{array}{l}\text { AlkTr, } \\
\text { MsTr }\end{array}$ & MsKs & $\mathrm{He}$ & Anph & Bal & $\mathrm{Ru}$ & Chenopodiaceae \\
\hline 8. Betula pendula Roth. & $\mathrm{Ph}$ & $\mathrm{Og} \operatorname{Tr}$ & Ms & $\mathrm{He}$ & Anph & Anch & Sil & Betulaceae \\
\hline 9. Bidens tripartita L. & $\mathrm{T}$ & $\operatorname{MsTr}$ & HgMs & $\mathrm{Sc}$ & Ent & Epz & $\begin{array}{l}\text { Pal- } \\
\text { Pr }\end{array}$ & Asteraceae \\
\hline $\begin{array}{l}\text { 10. Calamagrostis epigeios } \\
\text { (L.)Roth }\end{array}$ & G & $\begin{array}{l}\mathrm{OgMs} \\
\mathrm{Tr}\end{array}$ & Ms & $\mathrm{ScHe}$ & Anph & Anch & $\begin{array}{l}\text { Pr- } \\
\text { Ps-Sil }\end{array}$ & Poaceae \\
\hline $\begin{array}{l}\text { 11. Centaurea borysthenica } \\
\text { Grun. }\end{array}$ & $\mathrm{HKr}$ & $\operatorname{Og} \operatorname{Tr}$ & MsKs & $\mathrm{He}$ & Ent & Anch & Ps & Asteraceae \\
\hline $\begin{array}{l}\text { 12. Chamaecytisus } \\
\text { borysthenicus (Grun.) } \\
\text { Klaskova }\end{array}$ & $\mathrm{Ch}$ & $\operatorname{Og} \operatorname{Tr}$ & $\mathrm{KsMs}$ & $\mathrm{He}$ & Ent & Bal & St-Ps & Fabaceae \\
\hline 13. Chondrilla juncea L. & $\mathrm{HKr}$ & $\operatorname{Og} \operatorname{Tr}$ & MsKs & $\mathrm{He}$ & Ent & Anch & Ru-Ps & Asteraceae \\
\hline 14. Convolvulus arvensis L. & G & MsTr & MsKs & $\mathrm{ScHe}$ & $\begin{array}{l}\text { Ent, } \\
\mathrm{Ah}\end{array}$ & $\begin{array}{l}\text { Bal, } \\
\text { Bar }\end{array}$ & $\mathrm{Ru}$ & Convolvulaceae \\
\hline $\begin{array}{l}\text { 15. Dianthus campestris } \\
\text { Bieb. }\end{array}$ & $\mathrm{HKr}$ & $\underset{\mathrm{Tr}}{\mathrm{OgMg}}$ & KsMs & $\mathrm{ScHe}$ & Ent & Bal & $\begin{array}{l}\text { St-Ps- } \\
\mathrm{Ru}\end{array}$ & Caryophillaceae \\
\hline $\begin{array}{l}\text { 16. Erodium cicutarium } \\
\text { (L.)L'Her. }\end{array}$ & $\mathrm{T}$ & OgTr & MsKs & $\mathrm{ScHe}$ & Ent & $\begin{array}{c}\mathrm{KrG} \\
\mathrm{ch}\end{array}$ & St-Ru & Geraniaceae \\
\hline $\begin{array}{l}\text { 17. Euphorbia sequierana } \\
\text { Neck. }\end{array}$ & $\mathrm{HKr}$ & $\operatorname{MsTr}$ & Ks & $\mathrm{He}$ & $\begin{array}{l}\text { Ent, } \\
\text { Anph }\end{array}$ & Ach & $\begin{array}{c}\text { Pr- } \\
\text { Ps-St }\end{array}$ & Euphorbiaceae \\
\hline $\begin{array}{l}\text { 18. Festuca beckeri (Hack.) } \\
\text { Trautv. }\end{array}$ & $\mathrm{HKr}$ & $\operatorname{Og} \operatorname{Tr}$ & Ks & $\mathrm{He}$ & Anph & Bal & Ps-St & Poaceae \\
\hline 19. Fumaria officinalis L. & $\mathrm{T}$ & $\operatorname{MsTr}$ & KsMs & $\mathrm{He}$ & Ent & Bar & $\mathrm{Ru}$ & Fumariaceae \\
\hline 20. Galium verum L. & $\mathrm{HKr}$ & $\begin{array}{l}\text { OgMs } \\
\operatorname{Tr}\end{array}$ & KsMs & $\mathrm{ScHe}$ & Ent & Bal & Sil-St & Rubiaceae \\
\hline 21. Geum urbanum L. & $\mathrm{HKr}$ & $\begin{array}{l}\mathrm{OgMg} \\
\mathrm{Tr}\end{array}$ & Ms & $\mathrm{ScHe}$ & Ent & Epz & $\begin{array}{l}\mathrm{Ru}- \\
\text { Sil }\end{array}$ & Rosaceae \\
\hline $\begin{array}{l}\text { 22. Helichrysum arenarium } \\
\text { (L.) Moench }\end{array}$ & $\mathrm{HKr}$ & $\operatorname{Og} \operatorname{Tr}$ & MsKs & $\mathrm{He}$ & Ent & Anch & St-Ps & Asteraceae \\
\hline 23. Hieracium umbellatum L. & $\mathrm{HKr}$ & OgTr & MsKs & $\mathrm{ScHe}$ & Ent & Anch & $\begin{array}{l}\text { St-Ps- } \\
\text { Pr }\end{array}$ & Asteraceae \\
\hline $\begin{array}{l}\text { 24. Hierochloe odorata } \\
\text { (L.)Beauv. }\end{array}$ & G & $\begin{array}{l}\text { OgMs } \\
\text { Tr }\end{array}$ & KsMs & $\mathrm{ScHe}$ & Anph & Bal & $\begin{array}{l}\text { St-Pr- } \\
\text { Sil }\end{array}$ & Poaceae \\
\hline 25. Hypericum perforatum L. & $\mathrm{HKr}$ & $\operatorname{Og} \operatorname{Tr}$ & MsKs & $\mathrm{ScHe}$ & Ent & Bal & Sil-Pr & Huperziaceae \\
\hline $\begin{array}{l}\text { 26. Knautia arvensis } \\
\text { (L.)Coult. }\end{array}$ & $\mathrm{HKr}$ & $\mathrm{MsTr}$ & KsMs & $\mathrm{He}$ & $\begin{array}{l}\text { Ent, } \\
\text { P.a. }\end{array}$ & Bal & St-Pr & Dipsacaceae \\
\hline
\end{tabular}




\begin{tabular}{|c|c|c|c|c|c|c|c|c|}
\hline & & & & & & & \multicolumn{2}{|c|}{ Закінчення табл. 1} \\
\hline 1 & 2 & 3 & 4 & 5 & 6 & 7 & 8 & 9 \\
\hline $\begin{array}{l}\text { 27. Koeleria sabuletorum } \\
\text { (Domin)Klok. }\end{array}$ & $\mathrm{HKr}$ & $\mathrm{Og} \operatorname{Tr}$ & MsKs & $\mathrm{He}$ & Anph & Bal & Ps-St & Poaceae \\
\hline 28. Lactuca serriola Torner. & $\begin{array}{l}\mathrm{T}, \\
\mathrm{HKr}\end{array}$ & $\mathrm{MsTr}$ & KsMs & $\mathrm{He}$ & Ent & Anch & $\mathrm{Ru}$ & Asteraceae \\
\hline 29. Lotus ucrainicus Klok. & $\mathrm{HKr}$ & $\operatorname{MsTr}$ & KsMs & $\mathrm{He}$ & Ent & Ach & St-Pr & Fabaceae \\
\hline $\begin{array}{l}\text { 30. Melica transsilvanica } \\
\text { Schur }\end{array}$ & $\mathrm{HKr}$ & $\mathrm{MsTr}$ & KsMs & $\mathrm{ScHe}$ & Anph & Anch & $\begin{array}{l}\text { Sil- } \\
\text { St- } \\
\text { Chs }\end{array}$ & Poaceae \\
\hline 31. Pinus sylvestris L. & $\mathrm{Ph}$ & $\operatorname{Og} \operatorname{Tr}$ & Ks & $\mathrm{He}$ & Anph & Anch & Sil & Pinaceae \\
\hline 32. Poa bulbosa L. & $\mathrm{HKr}$ & $\begin{array}{l}\mathrm{OgMs} \\
\mathrm{Tr}\end{array}$ & MsKs & $\mathrm{He}$ & Anph & Bal & $\mathrm{Ru}-\mathrm{St}$ & Poaceae \\
\hline $\begin{array}{l}\text { 33. Polygonatum odoratum } \\
\text { (Mill.)Druce }\end{array}$ & $\mathrm{G}$ & $\mathrm{OgTr}$ & Ms & $\mathrm{ScHe}$ & Ent & Endz & Sil & Liliaceae \\
\hline 34. Populus tremula L. & $\mathrm{Ph}$ & $\begin{array}{l}\mathrm{OgMs} \\
\mathrm{Tr}\end{array}$ & $\mathrm{HgMs}$ & $\mathrm{ScHe}$ & Ent & Anch & Sil & Salicaceae \\
\hline 35. Quercus robur L. & $\mathrm{Ph}$ & $\begin{array}{l}\text { AlkTr, } \\
M g T r\end{array}$ & MsKs & $\mathrm{ScHe}$ & Ent & Synz & Sil & Fagaceae \\
\hline $\begin{array}{l}\text { 36. Rhinanthus vernalis } \\
\text { (N.ZinG)Schischk. et SerG }\end{array}$ & $\mathrm{T}$ & $\begin{array}{l}\text { MsTr, } \\
\text { S\Par }\end{array}$ & Ms & $\mathrm{He}$ & Ent & Bal & $\mathrm{Ru}-\mathrm{Pr}$ & Scrophulariaceae \\
\hline 37. Rumex acetosa L. & $\mathrm{HKr}$ & $\begin{array}{l}\mathrm{OgMs} \\
\mathrm{Tr}\end{array}$ & Ms & $\mathrm{ScHe}$ & Anph & Bal & Sil-Pr & Poligalaceae \\
\hline 38. Sambucus nigra L. & $\mathrm{nPh}$ & $\begin{array}{l}\mathrm{OgMg} \\
\mathrm{Tr}\end{array}$ & Ms & $\mathrm{ScHe}$ & Ent & Endz & Sil & Caprifoliaceae \\
\hline 39. Secale sylvestre Host & $\mathrm{T}$ & $\mathrm{Og} \operatorname{Tr}$ & MsKs & $\mathrm{He}$ & Anph & Epz & $\begin{array}{c}\mathrm{Ru}- \\
\mathrm{Ps}-\mathrm{St}\end{array}$ & Poaceae \\
\hline $\begin{array}{l}\text { 40. Sedum purpureum } \\
\text { (L.)Schult. }\end{array}$ & $\mathrm{G}$ & $\begin{array}{l}\mathrm{OgMs} \\
\mathrm{Tr}\end{array}$ & KsMs & $\mathrm{ScHe}$ & Ent & Bal & $\begin{array}{l}\text { St-Ps- } \\
\text { Sil }\end{array}$ & Crassulaceae \\
\hline 41. Sedum acre L. & $\mathrm{HKr}$ & $\operatorname{Og} \operatorname{Tr}$ & MsKs & $\mathrm{ScHe}$ & Ent & Hdch & St-Ps & Crassulaceae \\
\hline $\begin{array}{l}\text { 42. Sempervivum } \\
\text { ruthenicum Schnittsp. et } \\
\text { C.B.Lehm. }\end{array}$ & $\mathrm{HKr}$ & $\operatorname{Og} \operatorname{Tr}$ & $\mathrm{Ks}$ & $\mathrm{ScHe}$ & Ent & Bal & Sil-Ps & Crassulaceae \\
\hline $\begin{array}{l}\text { 43. Senecio vernalis } \\
\text { Waldst. et Kit. }\end{array}$ & $\begin{array}{l}\mathrm{T}, \\
\mathrm{HKr}\end{array}$ & $\begin{array}{l}\mathrm{OgMs} \\
\operatorname{Tr}\end{array}$ & KsMs & $\mathrm{ScHe}$ & Ent & Anch & $\mathrm{Ru}$ & Asteraceae \\
\hline 44. Seseli tortuosum L. & $\mathrm{HKr}$ & $\operatorname{Og} \operatorname{Tr}$ & MsKs & $\mathrm{He}$ & Ent & Perv & Ps-St & Apiaceae \\
\hline $\begin{array}{l}\text { 45. Setaria viridis (L.) } \\
\text { Beauv. }\end{array}$ & $\mathrm{T}$ & $\begin{array}{l}\mathrm{OgMs} \\
\mathrm{Tr}\end{array}$ & KsMs & $\mathrm{He}$ & Anph & Synz & $\mathrm{Ru}-\mathrm{Ps}$ & Poaceae \\
\hline 46. Silene tatarica (L.) Pers. & $\mathrm{HKr}$ & $\mathrm{MsTr}$ & $\mathrm{KsMs}$ & $\mathrm{ScHe}$ & Ent & Bal & Ps-Pr & Caryophillaceae \\
\hline 47. Stellaria graminea L. & $\mathrm{HKr}$ & $\begin{array}{l}\mathrm{OgMs} \\
\mathrm{Tr}\end{array}$ & KsMs & $\mathrm{ScHe}$ & Ent & Bal & $\begin{array}{l}\text { Sil- } \\
\text { Pr-Ru }\end{array}$ & Caryophillaceae \\
\hline 48. Stenactis annua Nees & $\begin{array}{l}\mathrm{T}, \\
\mathrm{HKr}\end{array}$ & $\mathrm{MsTr}$ & MsKs & $\mathrm{ScHe}$ & Ent & Anch & $\mathrm{Ru}$ & Asteraceae \\
\hline $\begin{array}{l}\text { 49. Stipa borysthenica } \\
\text { Klok. ex Prokud. }\end{array}$ & $\mathrm{HKr}$ & $\mathrm{OgTr}$ & MsKs & $\mathrm{ScHe}$ & Anph & $\begin{array}{l}\text { Anch } \\
\text {, Gch }\end{array}$ & Ps-St & Poaceae \\
\hline 50. Tanacetum vulgare L. & $\mathrm{HKr}$ & $\begin{array}{l}\mathrm{OgMg} \\
\mathrm{Tr}\end{array}$ & $\mathrm{KsMs}$ & $\mathrm{He}$ & Ent & Bal & St-Pr & Asteraceae \\
\hline 51. Tragopogon major Jacq. & $\mathrm{HKr}$ & $\mathrm{MsTr}$ & MsKs & $\mathrm{ScHe}$ & Ent & Anch & $\begin{array}{l}\text { Sil- } \\
\text { St-Ru }\end{array}$ & Asteraceae \\
\hline $\begin{array}{l}\text { 52. Ulmus carpinifolia } \\
\text { Rupp. ex G Suckow }\end{array}$ & $\mathrm{Ph}$ & MsTr & MsKs & $\mathrm{He}$ & Anph & Anch & Sil & Ulmaceae \\
\hline $\begin{array}{l}\text { 53. Vincetoxicum } \\
\text { hirundinaria Medik. }\end{array}$ & $\mathrm{HKr}$ & $\mathrm{MsTr}$ & MsKs & $\mathrm{ScHe}$ & Ent & Anch & St-Sil & Asclepidaceae \\
\hline 54. Viola lavrenkoana Klok. & $\mathrm{T}$ & $\mathrm{OgTr}$ & KsMs & $\mathrm{ScHe}$ & Ent & Ach & $\begin{array}{l}\text { Sil- } \\
\mathrm{Ru}\end{array}$ & Violaceae \\
\hline
\end{tabular}


На місцях згарищ утворюються трав'янисті угруповання з домінуванням жита дикого Secale sylvestre Host., костриці Беккера Festuca beckeri (Hack.) Trautv., тонконогу піщаного Koeleria sabuletorum (Domin)Klok, чаполочі пахучої Hierochloe odorata (L.)Beauv. На окремих ділянках у кварталі 179, виділ 14, рослинний покрив, через сухі умови, представлений моховим та лишайниковим шаром 3 незначною домішкою полину Маршала Artemisia marschalliana Spreng. та деяких сукулентів: очитка їдкого Sedum acre L. очитка рожевого Sedum purpureum (L.) Schult., молодила руського Sempervivum ruthenicum Schnittsp EtC.B.Lehm.

Флора досліджених ділянок нараховує 54 види вищих судинних рослин 3 28 родин. За чисельністю видів у рослинному покриві переважають рослини 3 родин Айстрові Asteraceae (13 видів, або $24 \%$ від загальної кількості) та Злакові Poaceae (9 видів, 17 \%) (табл. 2).

Таблиия 2

\section{Розподіл рослин на згарищах за родинами}

\begin{tabular}{|c|c|c|c|}
\hline $\begin{array}{c}\text { № } \\
\text { ח/П } \\
\end{array}$ & Родини & Кількість видів & $\%$ \\
\hline 1 & Asteraceae & 13 & 24,07 \\
\hline 2 & Poaceae & 9 & 16,67 \\
\hline 3 & Caryophillaceae & 3 & 5,56 \\
\hline 4 & Crassulaceae & 3 & 5,56 \\
\hline 5 & Fabaceae & 3 & 5,56 \\
\hline 6 & Alliaceae & 1 & 1,85 \\
\hline 7 & Apiaceae & 1 & 1,85 \\
\hline 8 & Asclepidaceae & 1 & 1,85 \\
\hline 9 & Betulaceae & 1 & 1,85 \\
\hline 10 & Brassicaceae & 1 & 1,85 \\
\hline 11 & Caprifoliaceae & 1 & 1,85 \\
\hline 12 & Chenopodiaceae & 1 & 1,85 \\
\hline 13 & Convolvulaceae & 1 & 1,85 \\
\hline 14 & Dipsacaceae & 1 & 1,85 \\
\hline 15 & Euphorbiaceae & 1 & 1,85 \\
\hline 16 & Fagaceae & 1 & 1,85 \\
\hline 17 & Fumariaceae & 1 & 1,85 \\
\hline 18 & Geraniaceae & 1 & 1,85 \\
\hline 19 & Huperziaceae & 1 & 1,85 \\
\hline 20 & Liliaceae & 1 & 1,85 \\
\hline 21 & Pinaceae & 1 & 1,85 \\
\hline 22 & Poligalaceae & 1 & 1,85 \\
\hline 23 & Rosaceae & 1 & 1,85 \\
\hline 24 & Rubiaceae & 1 & 1,85 \\
\hline 25 & Salicaceae & 1 & 1,85 \\
\hline 26 & Scrophulariaceae & 1 & 1,85 \\
\hline 27 & Ulmaceae & 1 & 1,85 \\
\hline 28 & Violaceae & 1 & 1,85 \\
\hline $\begin{array}{l}\text { Разом } \\
\text { видів } \\
\end{array}$ & 28 родин & 54 & 100 \\
\hline
\end{tabular}


3 життєвих форм переважають багаторічні трави: 32 види, або 59 \%. Однорічних трав - 12 видів (22 \%). Дерев та кущів 9 \% та 4 \% відповідно (табл. 3).

Таблиия 3

Розподіл рослин на згарищах за загальним габітусом та тривалістю життсвого циклу

\begin{tabular}{lcc}
\hline \multicolumn{1}{c}{ Життева форма } & Кількість видів & $\%$ \\
\hline Деревні рослини: & 7 & 13,0 \\
\multicolumn{1}{c}{ дерева } & 5 & 9,3 \\
кущі & 2 & 3,7 \\
Багаторічники & 32 & 59,3 \\
Дворічники & 3 & 5,6 \\
Однорічники & 12 & 22,2 \\
\hline Разом видів & 54 & 100 \\
\hline
\end{tabular}

Екоморфічний аналіз дозволяє виявити розподіл рослин по відношенню до основних екологічних факторів: трофність субстрату - трофоморфи, водний режим - гідроморфи, світовий режим - геліоморфи, адаптація до кліматичних умов - клімаморфи за Раункієром та адаптація рослинних організмів до умов конкретного біогеоценозу. 3 трофоморф переважають оліготрофи - 22 види, $41 \%$ (табл. 4).

Таблиия 4

\section{Розподіл рослин на згарищах за адаптацією рослин до живлення}

\begin{tabular}{lcc}
\hline \multicolumn{1}{r}{ Трофоморфи } & Кількість видів & $\%$ \\
\hline Оліготрофи & 22 & 40,7 \\
Мезотрофи & 12 & 27,8 \\
Олігомезотрофи & 11 & 20,4 \\
Олігомегатрофи & 4 & 7,4 \\
Алкотрофи & 2 & 3,7 \\
\hline Разом видів & 54 & 100 \\
\hline
\end{tabular}

3 гідроморф - мезоксерофіти 43 \% (табл. 5).

Таблиия 5

\section{Екологічний спектр рослин на згарищах за водним режимом}

\begin{tabular}{lcc}
\hline \multicolumn{1}{r}{ Гідроморфи } & Кількість видів & $\%$ \\
\hline Ксерофіти & 6 & 11,1 \\
Мезоксерофіти & 23 & 42,6 \\
Ксеромезофіти & 16 & 29,6 \\
Мезофіти & 7 & 13 \\
Гігромезофіти & 2 & 3,7 \\
\hline Разом видів & 54 & 100 \\
\hline 86
\end{tabular}


3 геліоморф - сціогеліофітів 52 \%, геліофітів 46 \% (табл. 6).

Таблиия 6

Екологічний спектр рослин на згарищах за адаптацією рослин до світла

\begin{tabular}{|c|c|c|}
\hline Геліоморфи & Кількість видів & $\%$ \\
\hline Геліофіти & 25 & 46,3 \\
\hline Сціофіти & 1 & 1,9 \\
\hline Сціогеліофіти & 28 & 51,9 \\
\hline Разом видів & 54 & 100 \\
\hline
\end{tabular}

Клімаморфи представлені гемікриптофітами - 54 \%, терофітами - $22 \%$, фанерофітами - $13 \%$ та геофітами - $11 \%$ (табл. 7).

Таблиия 7

Екологічний спектр рослин на згарищах за системою біологічних типів Раункісра (клімаморфи за Бельгардом)

\begin{tabular}{lcc}
\hline \multicolumn{1}{c}{ Клімаморфи } & Кількість видів & \% \\
\hline Фанерофіти & 7 & 13 \\
Гемікриптофіти & 29 & 53,7 \\
Геофіти & 6 & 11,1 \\
Терофіти & 12 & 22,2 \\
\hline Разом видів & 54 & 100 \\
\hline
\end{tabular}

3 ценоморф переважають сильванти - $28 \%$, степанти - $25 \%$ та рудеранти $23 \%$. Власне псамофітів, адаптованих до життя в піщаних ценозах, лише $15 \%$ від загальної кількості (табл. 8).

Таблиия 8

\section{Екологічний спектр рослин на згарищах за адаптацісю до біогеоценозу в цілому}

\begin{tabular}{|c|c|c|}
\hline Ценоморфи & Кількість видів & $\%$ \\
\hline Петрофіти & 1 & 1,9 \\
\hline Гелофіти & 1 & 1,9 \\
\hline Пратанти & 3 & 5,7 \\
\hline Псамофіти & 8 & 15,1 \\
\hline Рудеранти & 12 & 22,6 \\
\hline Сильванти & 15 & 28,3 \\
\hline Степанти & 13 & 24,5 \\
\hline Разом видів & 54 & 100 \\
\hline
\end{tabular}

\section{Висновки}

На місцях згарищ соснових насаджень на арені ріки Самари в межах ДП «Новомосковський військовий лісгосп» утворюються мезоксерофільні 
трав'янисті угруповання з домінуванням родин Айстрові та Злакові у видовому складі. За життєвими формами переважають багаторічні трави, здебільшого це гемікриптофіти. Наявність серед ценоморф високої кількості рудерантів свідчить про нестабільність біогеоценозів. Збереглись деякі лісові та бур'янисто-лісові рослини. У сухуватих умовах вселяються степові види. Зокрема, утворює угруповання ковила дніпровська Stipa borysthenica Klok. ex Prokud, занесена до Червоної книги України (відмічена у кварталі 137, виділ 10) [4, 7].

\section{Бібліографічні посилання}

1. Національна доповідь про стан техногенної та природної безпеки в Україні.https://undicz.dsns.gov.ua/ua/Nacionalna-dopovid-pro-stan-tehnogennoyi-taprirodnoyi-bezpeki-v-Ukrayini.html

2. Проект організації та розвитку лісового господарства державного підприємства «Новомосковський військовий лісгосп» Дніпропетровської області. Вільнянське лісництво. Таксаційний опис. 2010. 213 с.

3. Бельгард А.Л. Лесная растительность юго-востока УССР. К.: КГУ, 1950. $263 \mathrm{c}$.

4. Кучеревський В.В. Атлас рідкісних i зникаючих рослин Дніпропетровщини. К.: Фітосоціоцентр, 2001. 360 с.

5. Растительный и почвенный покров Присамарья Днепровского / Алексеев Ю.Е., Бельгард А.Л., Губанов И.А. и др. Д.: ДГУ, 1986. 64 с.

6. Тарасов В.В. Флора Дніпропетровської та Запорізької областей. Судинні рослини. Біолого-екологічна характеристика видів. Д.: Вид. ДНУ, 2005. $276 \mathrm{c}$.

7. Червона книга Украӥни. Рослинний світ. К.: Вид. «Глобалконсалтинг», 2009. $912 \mathrm{c}$.

Надійшла до редколегії 04.09.2019 p. 